\title{
Quantifying hydropedological properties of terroir at different scales. Implications in vineyard characteristics of three viticultural regions of the Iberian Peninsula.
}

\author{
Joaquín Cámara $^{1}$, Alberto Lázaro ${ }^{2}$ and Vicente Gómez-Miguel ${ }^{1}$ \\ ${ }^{1}$ Universidad Politécnica de Madrid, Dpto. Producción Agraria, ETSIAAB, 28040 Madrid, Spain \\ ${ }^{2}$ Universidad de Burgos, Dpto. Biotecnología y Ciencia de los Alimentos, Facultad de Ciencias, 09001 Burgos, Spain
}

\begin{abstract}
Summary. Hydropedology is a branch of science that studies the spatial and temporal variability of the soil water content, knowledge needed for a proper application of precision agriculture techniques in viticulture. This work aims to quantify at different scales hydropedological properties of viticultural regions with different geological, climatic and cultural characteristics, and it also aims to explore the relationships between these hydropedological properties and the vineyard characteristics within the studied regions. The structure of drainage networks at landscape scale and the heterogeneity of the soil particle size distribution are the hydropedological properties considered for the purpose of this study. The three winegrowing regions are the Região Demarcada do Douro, in Portugal, and the D.O. Arribes and D.O. Campo de Borja, in Spain, involving a total area of $4,144 \mathrm{~km}^{2}$. The datasets for this work are the soil maps of the three regions scale $1 / 25,000$, the digital terrain model, and the spatial database with the characteristics of the vineyards within the study area. Qualitative relationships have been established between landscape attributes, vineyard characteristics and physical soil properties. Results show that quantifying hydropedological properties using complexity measures provides innovative information of terroirs that could have multiple applications in terroir zoning studies.
\end{abstract}

\section{Introduction}

Hydropedology is an emerging interdisciplinary science that studies interactive pedologic and hydrologic processes and properties in the thin layer of the Earth's surface and near-surface terrestrial environment from the top of the vegetation canopy to the bottom of the weathering zone [1]. Environmental processes within this layer, including mass and energy exchange, soil formation, streamflow generation, and landscape evolution are key processes to sustaining biodiversity and humanity [2], that also influence the vineyards development.

Hydropedology aims to understand the spatial and temporal variability of soil water content, which knowledge is required for implementing precision agriculture techniques in viticulture.

The objectives of this work are to quantify at different scales hydropedological properties of viticultural regions with different geological, climatic and cultural characteristics, and the exploration of the relationships between these hydropedological properties and the vineyard characteristics in the three studied regions.

The hydropedological properties quantified in this study are the structure of drainage networks at landscape scale, which represent the surficial water movements across the landscape, and the soil texture heterogeneity at pedon scale, that seems to be closely related to the storage and release of water in soils [3].

\section{Material and methods}

\subsection{Study area}

The study area involves three wine growing regions of the Iberian Peninsula: the Regiao Demarcada do Douro, in Portugal, and the D.O. Arribes and the D.O. Campo de Borja, in Spain (Figure 1). These regions cover a total area of $4,144 \mathrm{~km}^{2}, 461 \mathrm{~km}^{2}$ of which are under vineyard. RD Douro and DO Arribes are in the Northwestern part of the Iberian Peninsula, within the Duero/Douro river basin, while DO Campo de Borja is in the Northeastern part, within the Ebro river basin. The geology of RD Douro and DO Arribes consists of metamorphic rocks (schists, slates, and gneisses) and 
igneous rocks (granites and granitoids) of the Iberian Hercynian Massif. In contrast, the geology of DO Campo de Borja is formed by Ordovician and Triassic materials, along with Quaternary materials of the Ebro river basin in the lower lands of the DO.

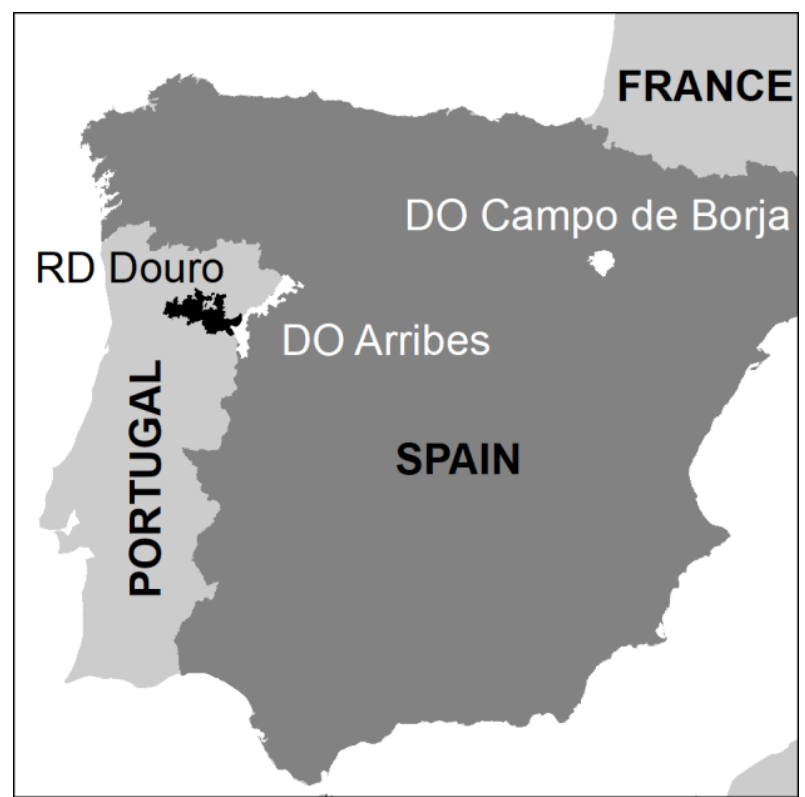

Figure 1. Studied wine growing regions (graphic scale $1 / 12,000,000)$.

\subsection{Data set}

Three sources of information of each region have been used in this study; the soil map (scale1/25,000), the digital terrain model (DTM), and the vineyard information contained in the official register of each winegrowing region.

Soil maps of these areas [4-6] include analytical and morphological data of 2,192 soil profiles and have been used to estimate soil texture heterogeneities.

The DTM resolution of DO Arribes and DO Campo de Borja is 5 meters, while DTM of RD Douro is 10 meters-resolution. DTMs have been used to generate the surficial drainage networks of these regions (Figure 2) by means of the Hydrology Toolbox of ArcGIS 10.1, which uses the D8 algorithm for networks extraction developed by O'Callaghan and Mark [7]. The threshold area to initiate channelization has been established at $10,000 \mathrm{~m}^{2}$, which has been successfully used in previous works [8-9].

Vineyard information corresponds to data from the official viticultural registries of the three winegrowing regions which include individualized data of the vineyard plots such as plant density, vine variety, altitude, exposition and planting date. This information has been joined to georeferenced information of the agricultural plots for the cartographic operations carried out.

\subsection{Quantifying hydropedological properties}

The hydropedological properties studied in this work have been the structure of drainage networks at landscape scale and the heterogeneity of the soil particle size distribution at pedon scale.

The structure of drainage networks has been quantified by means of fractal techniques.

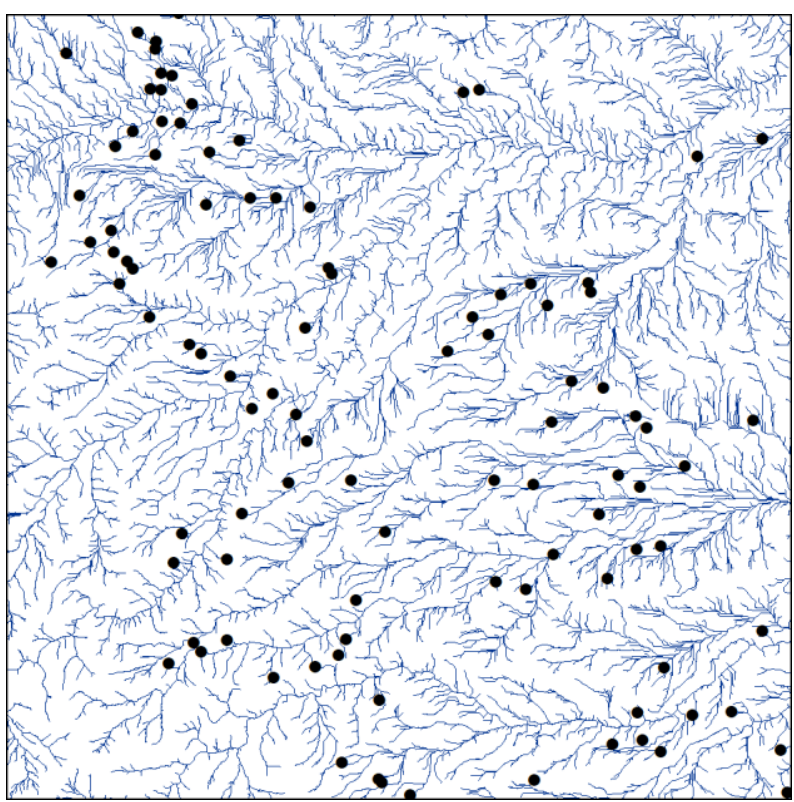

Figure 2. Portion of the drainage network of the DO Campo de Borja with the locations of same soil profiles (graphic scale $1 / 150,000)$.

The fractal dimension of the networks that overlap the winegrowing regions has been estimated using the box counting method [10-11], where the objects to be analyzed are covered by a regular grid of side $r$. The number of grid boxes containing the drainage network is counted $N(r)$, and then, the value $r$ is repeteadly halved obtaining the series of $N_{\mathrm{i}}$ values. Taking a reference box size $\left(r_{1}\right)$, the size factor $\left(s_{\mathrm{i}}\right)$ is calculated using the following equation.

$$
s_{\mathrm{i}}=r_{\mathrm{i}} / r_{1}
$$

When $r_{\mathrm{i}}$ decreases the following expression converges to a finite value defined as box counting dimension $(D)$.

$$
D \approx \frac{\log N_{i}}{\log \left(\frac{1}{s_{i}}\right)}
$$

The reference box size $\left(r_{1}\right)$ has been established at $320 \mathrm{~m}$, and the other box sizes used in the estimations have been $160 \mathrm{~m}, 80 \mathrm{~m}, 40 \mathrm{~m}, 20 \mathrm{~m}$ and $10 \mathrm{~m}$.

The heterogeneity of the soil particle size distribution has been measured using the Balanced Entropy Index (BEI), based on Shannon's entropy and recently introduced in terroir studies [12]. This index was proposed by Martín et al. [13] and it is given by the following equation

$$
B E I=\frac{\sum_{i} P_{i} \log P_{i}}{\sum_{i} P_{i} \log l_{i}}
$$


where the numbers $l_{i}$ are the scale lengths of the three basic size intervals $\left(l_{1}=0.001, l_{2}=0.024\right.$ and $l_{3}=$ $0.975)$ and $P_{i}$ are the soil's clay-silt-sand fractions. The $B E I$ above provides a continuous parameterization, from 0 to 1 , of the soil texture (Figure 3 ) that can be easily computed from textural data.

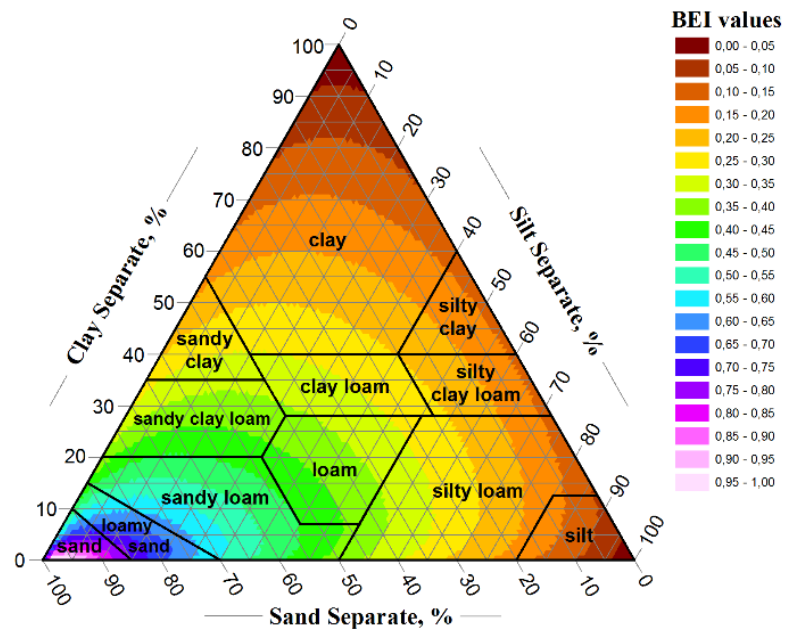

Figure 3. Distribution of BEI values on the USDA textural triangle [14].

The BEI has been calculated in the 3,018 soil samples included in the databases of the soil maps $1 / 25,000$ of the three regions. An average value of BEI was obtained for each winegrowing region under study.

\section{Results}

\subsection{Fractal dimension of drainage networks}

Results of the fractal dimension $(D)$ of the three drainage networks are shown in Table 1 .

Table 1. Box counting results

\begin{tabular}{lcc}
\hline $\begin{array}{c}\text { Studied } \\
\text { region }\end{array}$ & $\begin{array}{c}\text { Fractal } \\
\text { dimension }\end{array}$ & $\begin{array}{c}\text { Coefficient of } \\
\text { determination for } \\
\text { D estimation } \\
\left(\mathrm{R}^{2}\right)\end{array}$ \\
\hline RD Douro & 1.1610 & 0.989 \\
DO Arribes & 1.2208 & 0.993 \\
$\begin{array}{l}\text { DO Campo de } \\
\text { Borja }\end{array}$ & 1.2842 & 0.991 \\
\hline
\end{tabular}

The fractal nature of drainage networks, and the suitability of the followed method to characterize their structure, are supported by the high values of $\mathrm{R}^{2}$ obtained for the fractal dimension estimations, which are higher than 0.980 in the three cases.

$D$ values of drainage networks range from 1.1610, in RD Douro, to 1.2842 in DO Campo de Borja.

Results show that fractal dimensions of drainage networks in regions formed by metamorphic and igneous rocks (RD Douro and DO Arribes) is lower than in regions where quaternary materials have a significant presence (DO Campo de Borja). Moreover, $D$ value in RD Douro, where metamorphic areas are predominant, is lower than in DO Arribes, where granitic areas cover a wider part of the region. These results are consistent with those obtained in previous works [9], where fractal dimensions in granitic areas is higher than in metamorphic areas.

\subsection{Soil texture heterogeneity}

Results of $B E I$ calculations are showed in Table 2.

Table 2. Balanced Entropy Index results

\begin{tabular}{lcc}
\hline $\begin{array}{c}\text { Studied } \\
\text { region }\end{array}$ & $\begin{array}{c}\text { Soil samples } \\
\text { with textural } \\
\text { data }\end{array}$ & $\begin{array}{c}B E I \\
(\text { mean } \pm \mathrm{CI})\end{array}$ \\
\hline RD Douro & 1,510 & $0.457 \pm 0.003 \mathrm{~b}$ \\
$\begin{array}{l}\text { DO Arribes } \\
\text { DO Campo de }\end{array}$ & 711 & $0.530 \pm 0.005 \mathrm{c}$ \\
Borja & 797 & $0.303 \pm 0.004 \mathrm{a}$ \\
\hline \multicolumn{3}{l}{ Different letters in a column indicate significant differences $(P<0.05)$. LSD test }
\end{tabular}

Significant statistical differences have been established between the values of $B E I$ obtained in the three studied regions. The regional average $B E I$ values range from $0.303 \pm 0.004$, in DO Campo de Borja, to $0.530 \pm 0.005$, in DO Arribes. These results quantitatively show that metamorphic and granitic rocks evolve in soils with coarser soil textures than soils developed in quaternary materials.

Results show that $B E I$ values are higher in areas mostly formed by granitic materials (DO Arribes) than in regions where metamorphic rocks are predominant (RD Douro), which is consistent with the results and conclusions of previous works [14-15].

Results suggest that the winegrowing regions could be characterized by a $B E I$ value that reflects similarities and differences between regions. This finding complements those results obtained in the previous works cited above, which showed that BEI values are useful to discriminate between areas with different lithological materials within the same winegrowing region.

\subsection{Hydropedological properties and vineyard characteristics}

In this preliminary study, planting density $(n)$ has been chosen, amongst the vineyard characteristics included in the managed databases, to explore the relationships between the hydropedological and vineyard properties of the three studied winegrowing regions. In order to compare plant density with the other variables, a regional average value of plant density has been calculated for each winegrowing region (Table 3 ).

Table 3. Vineyard planting density

\begin{tabular}{ccc}
$\begin{array}{c}\text { Studied } \\
\text { region }\end{array}$ & $\begin{array}{c}\text { Plots with } \\
\text { density data }\end{array}$ & $\begin{array}{c}\text { Planting density }(n) \\
(\text { mean } \pm \mathrm{CI})\end{array}$ \\
\hline RD Douro & 138,786 & $6,670 \pm 8 \mathrm{c}$
\end{tabular}




$\begin{array}{llcl}\text { DO Arribes } & & 715 & 2,138 \pm 57 \mathrm{a} \\ \text { DO Campo de } & 1,824 & 2,406 \pm 65 \mathrm{~b} \\ \text { Borja } & & & 1,84\end{array}$

Different letters in a column indicate significant differences $(P<0.05)$. LSD test

Unfortunately, not every vineyard plot included in the official registries has planting density information. However, the number of plots with proper information allowed the obtention of significant statistical results.

As happened with BEI results, significant statistical differences could be established between the average planting densities (n) of the three studied regions. $n$ values range from $2,138 \pm 57$, in DO Arribes, to $6,670 \pm 8$, in RD Douro. These results quantitatively show that cultural practices in RD Douro are significantly different than those observed in DO Arribes and DO Campo de Borja.

Results shown in Table 1, Table 2 and Table 3 have been plot together in Figure 4.

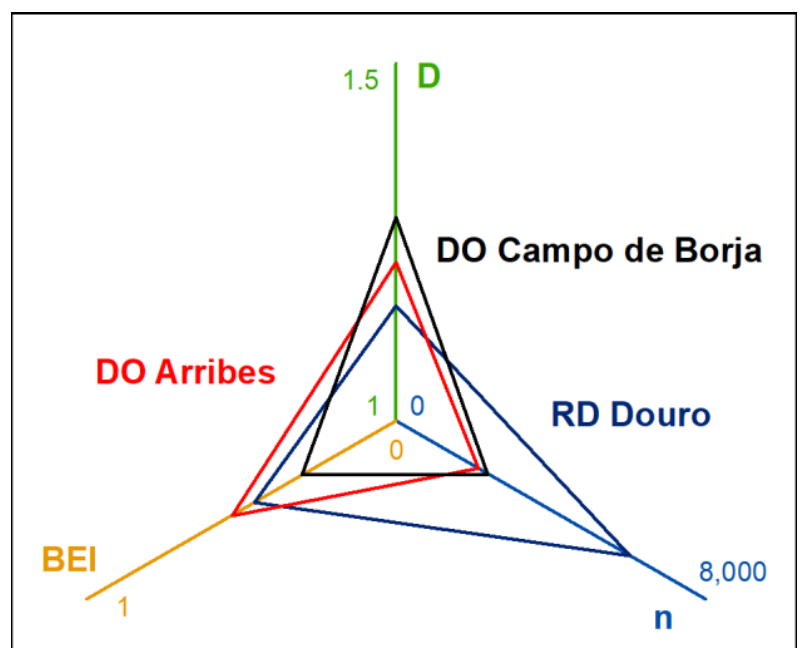

Figure 4. Graphic representation of the main results.

Results suggest that, in areas where vineyards irrigation is restricted for absence of infrastructures (DO Arribes), or water availability (DO Campo de Borja), the fractal dimension of drainage networks is linearly related to plant density in vineyards. This is not the case of RD Douro where the steep inclination of the slopes, and the availability of water from the Duero river, has resulted in specific cultural practices modifying this relationship.

Average values of $B E I$ and planting density in DO Campo de Borja and DO Arribes show the same trend observed at plot scale in previous works in RD Douro [12], where discriminating among different lithologies higher values of $B E I$ were related to lower values of planting densities in vineyards.

According to the obtained results, $B E I$ and $D$ seem to be linearly related in areas with comparable geologic materials such as RD Douro and DO Arribes, where lower values of $D$ are related to lower values of $B E I$.

\section{Conclusions}

The relationship between the structure of drainage networks at landscape scale, the heterogeneity of the soil particle sizes distribution at pedon scale and the planting density of vineyards was explored in three winegrowing regions of the Iberian Peninsula.

The quantification of hydropedological properties in winegrowing regions provides innovative information of terroirs that, further to be useful to characterize them, could be employed to establish environmental relationships or differences between regions.

Although additional studies, including other hydropedological and vineyard properties, are still to be performed, the potential uses of complexity measures in terroir studies, such as the fractal dimension of the drainage networks or the Balanced Entropy Index, are promising.

\section{References}

1. National Council Research, Basic research opportunities in the earth sciences (Natl. Acad. Press, Washington, DC, 2001)

2. H. Lin, J.W. Hopmans, D. Richter, Vadose Zone J. 10, 781-782 (2011)

3. M.A. Martín, Y.A. Pachepsky, J.M. Rey, J. Taguas, W.J. Rawls, Soil Science 170, 759-766 (2005)

4. V. Gómez-Miguel, V. Sotés, J. Cámara, G. Hernando, Delimitación de las zonas vitícolas de la DO Arribes (Univ. Politécnica de Madrid, Madrid, 2011) Technical report not published.

5. V. Gómez-Miguel, V. Sotés, J. Cámara, G. Hernando, Zonagem e Ordenamento da cultura da vinha do Vale do Douro(Portugal). (Univ. Politécnica de Madrid, Madrid, 2011) Technical report not published.

6. V. Gómez-Miguel, V. Sotés, J. Cámara, A. Martínez, Zonificación de los terroir vitícolas de la DO Campo de Borja (Univ. Politécnica de Madrid, Madrid, 2015) Technical report not published.

7. J. O'Callaghan, D.M. Mark, Comput. Vision Graph. 3, 323-344 (1984)

8. A.B. Ariza-Villaverde, F.J. Jiménez-Hornero, E. Gutiérrez, Geomorphology, 197, 85-95 (2013)

9. J. Cámara, V. Gómez-Miguel, M.A. Martín, Pure Appl. Geophys. 173, 945-961 (2016)

10. D. Russel, J. Hanson, E. Otto, Physical Rev. Letters 45, 1175-1178 (1980)

11. I. Rodríguez-Iturbe, A. Rinaldo, Fractal river basins: Chance and self-organization (Cambridge Univ. Press, Cambridge, 1997)

12. J. Cámara, A. Lázaro, V. Gómez-Miguel, Proceedings of the XI International Terroir Congress, 365-370 (Southern Oregon University, Ashland, USA, 2016)

13. M.A. Martín, J.M. Rey, J. Taguas, Ecol. Model. 182, 221-228 (2005)

14. J. Cámara, V. Gómez-Miguel, M.A. Martín, Geoderma 287, 157-163 (2017)

15. J. Cámara, M.A. Martín, V. Gómez-Miguel, Fractals 23, 1540007 (2015) 